\title{
Protein Needles as Molecular Templates for Artificial Metalloenzymes
}

$\operatorname{AUTHOR}(\mathrm{S})$ :

Inaba, Hiroshi; Kitagawa, Susumu; Ueno, Takafumi

\section{CITATION:}

Inaba, Hiroshi ...[et al]. Protein Needles as Molecular Templates for Artificial Metalloenzymes. Israel Journal of Chemistry 2014, 55(1): 40-50

\section{ISSUE DATE:}

2014-09-18

URL:

http://hdl.handle.net/2433/200242

\section{RIGHT:}

This is the peer reviewed version of the following article: Inaba, H., Kitagawa, S. and Ueno, T. (2015), Protein Needles as Molecular Templates for Artificial Metalloenzymes. Isr. J. Chem., 55: 40-50, which has been published in final form at http://dx.doi.org/10.1002/ijch.201400097. This article may be used for non-commercial purposes in accordance with Wiley Terms and Conditions for Self-Archiving.; この論文は出版社版でありません。引用の際には出版社版をご確認ご 利用ください。; This is not the published version. Please cite only the published version. 


\title{
Protein needles as molecular templates for artificial metalloenzymes
}

\author{
Hiroshi Inaba, ${ }^{[a]}$ Susumu Kitagawa, ${ }^{[a, b]}$ and Takafumi Ueno ${ }^{[b, c]}$
}

\begin{abstract}
Construction of artificial metalloenzymes based on protein assemblies is a promising strategy for development of new catalysts because the three-dimensional nanostructures of proteins with defined individual sizes can be used as molecular platforms which allow arrangement of catalytic active centers on their surfaces. Protein needles/tubes/fibers are suitable for supporting various functional molecules including metal complexes, synthetic molecules, metal nanoparticles, and enzymes with high density and precise locations. Compared to bulk systems, the protein tube- and fiber-based materials have higher activities for catalytic reactions and electron transfer, as well as enhanced functions
\end{abstract}

used in electronic devices. The natural and synthetic protein tubes and fibers are constructed by self-assembly of monomer proteins or peptides. For more precise designs of arrangements of metal complexes, we have developed a new conceptual framework based on isolation of a robust needle structure from the cell-puncturing domains of bacteriophage. The artificial protein needle shows great promise for use in creating efficient catalytic systems by providing the means to arrange the locations of various metal complexes on the protein surface. In this account, we discuss the recent development of protein needle-based metalloenzymes and the future developments we are anticipating in this field.

\section{Introduction}

Protein assemblies have distinct three-dimensional structures that are directly associated with their functions. Based on naturally designed and defined size and structure, the protein assemblies have been shown to hold promise as molecular platforms for construction of artificial metalloenzymes. ${ }^{[1-4]}$ Figure 1 shows a series of representative protein assemblies. Several enzymes such as myoglobin contain metal cofactors as a catalytic center (Figure 1a). Modulation of catalytic active sites by site-directed mutagenesis and introduction of nonnatural metal cofactors is a general method that can be used to construct artificial metalloenzymes. Protein cages such as ferritin are formed by self-assembly of monomer proteins (Figure 1b). The interior spaces of the cages provide isolated environments with limited sizes. These interior cavities have been utilized to synthesize monodisperse nanoparticles and achieve catalytic reactions by accumulation of metal complexes and metal nanoparticles. Protein needles/tubes/fibers, which are constructed by self-assembly of monomer proteins or peptides, have been utilized to align various functional molecules such as metal complexes, peptides, and proteins (Figure 1c). Particular advantages provided by the protein needles include the ability to display functional molecules with high density and regularity along the long axis, the ability to alter the distance between the molecules by changing bio-conjugation locations, and the ability to display different functional molecules. Thus, protein- and peptide-based needles/tubes/fibers have been utilized to create biomaterials such as catalysts, sensors, electronic devices, drug delivery systems and imaging reagents. ${ }^{[3,5-}$

${ }^{7]}$ Here we describe the results of recent research in the area of tube- and fiber-based metalloenzymes and our needle-based metalloenzymes which employ different design strategies using component protein assemblies from unique examples of bio-supramolecular machinery.

\section{General functionalization of tubular protein assemblies}

Several viruses such as tobacco mosaic virus (TMV), ${ }^{[8]}$ M13 virus, and potato virus X (PVX) ${ }^{[9]}$ which represent natural examples of filamentous assemblies, are widely used in efforts to design new materials (Figure 2ac). ${ }^{[10,11]}$ The viruses are composed of protein shells that can be formed by self-assembly of hundreds to thousands identical monomer subunit proteins with

[a] H. Inaba, Prof. S. Kitagawa Department of Synthetic Chemistry and Biological Chemistry,

Graduate School of Engineering

Kyoto University

Katsura, Kyoto 615-8510 (Japan)

[b] Prof. S. Kitagawa, Prof. T. Ueno

Institute for Integrated Cell-Material Sciences (WPIiCeMS)

Kyoto University

Yoshida, Sakyo-ku, Kyoto 606-8501 (Japan)

[c] Prof. T. Ueno

Graduate School of Bioscience and Biotechnology

Tokyo Insitute of Technology

Nagatsuda, Midori-ku, Yokohama 226-8501 (Japan)

phone and fax: (+81) 45-924-5806 
a
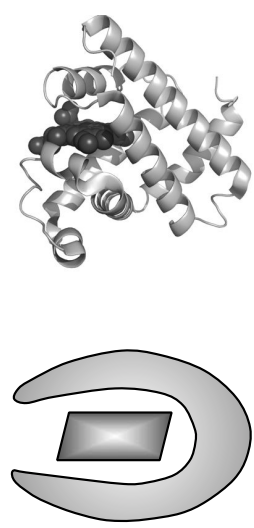

Tuning of active site b
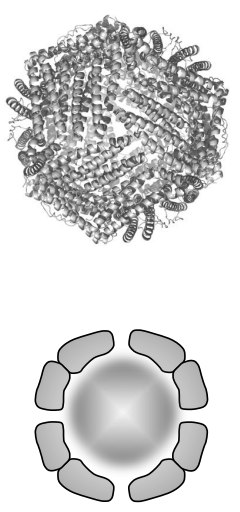

Isolated environment
C
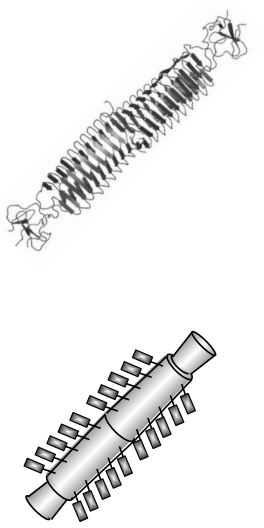

Alignment of functional molecules

Figure 1. Typical protein assemblies with distinct threedimensional structures. (a) Myoglobin (cofactor is shown as space filling models). (b) Ferritin (nanocage). (c) Needle reconstructed from bacteriophage T4. The structures were taken from PDB ID: 4MBN, 1DAT, and $3 \mathrm{~A} 1 \mathrm{M}$, respectively.

a

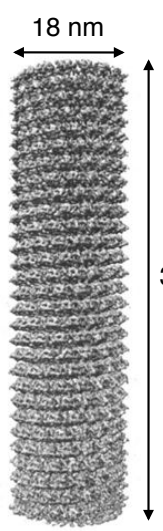

b

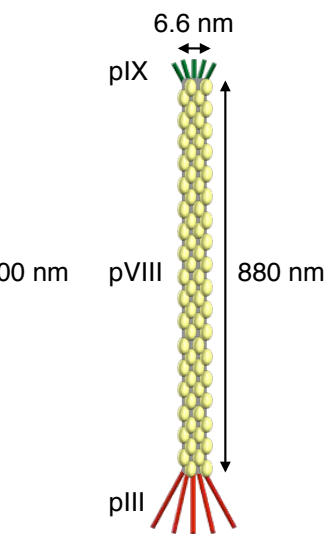

C

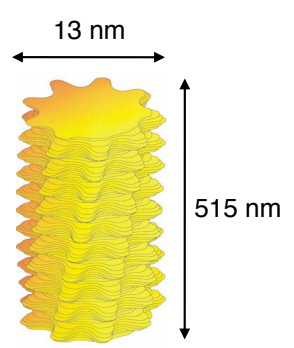

d

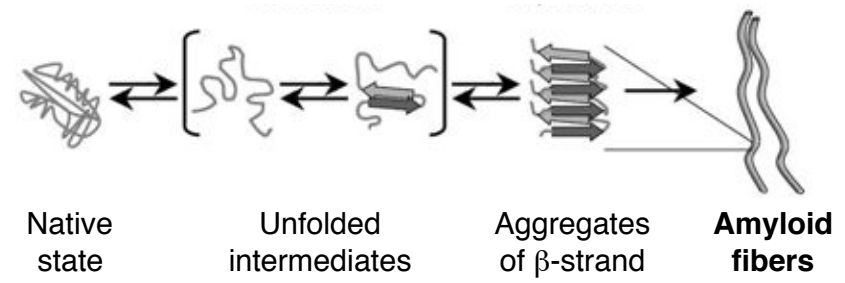

e

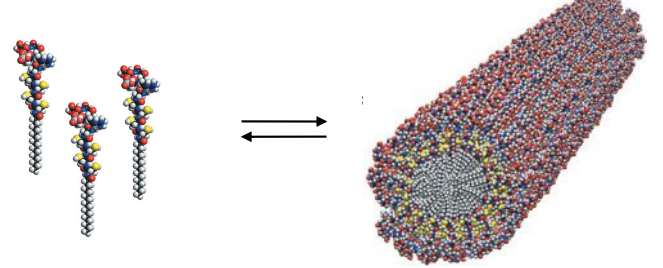

Figure 2. Natural and synthetic protein nanotubes. (a) TMV. (b) M13 virus. (c) PVX. (d) Amyloid-like fibers. (e) Peptide amphiphile nanofiber. Reproduced with permission for (a) and (c), (d), and (e) from Elsevier, Wiley, and AAAS, respectively, see ref. $8,9,13$, and 17 .
Hiroshi Inaba received his

M.Sc. from Nagoya University, Japan in 2011. He worked as a JSPS fellow at the Institute for Integrated Cell-Material Sciences (iCeMS) at Kyoto University from 2012 to 2014. $\mathrm{He}$ is pursuing his $\mathrm{PhD}$ degree in the Graduate School of Engineering of Kyoto University. His current research focuses on the molecular design of artificial protein assembly based on chemical and genetic modifications toward construction of new bionanomaterials.

Susumu Kitagawa received his $\mathrm{Ph}$. D. at Kyoto University in 1979. He became Assistant Professor (1979), Lecturer (1983), and Associate Professor (1988) at Kinki University. He was promoted to Professor of Inorganic Chemistry at Tokyo

Metropolitan University in 1992 , and moved to Kyoto University as Professor of Functional Chemistry in 1998. He had been a visiting Scientist in $F$. A Cotton Laboratory, Texas A \& $M$ University, during the period of 1986-1987, and an exchange

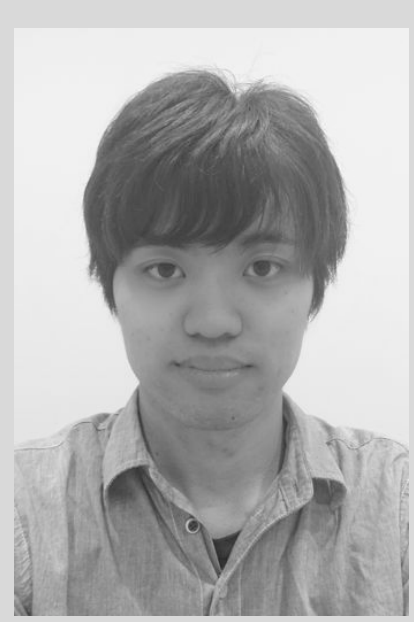

professor in City University of New York in 1996. He is now Director of Institute for Integrated Cell-Material Sciences (iCeMS) at Kyoto University launched by Japanese Government (2007). His main research fields are coordination chemistry, in particular, chemistry of coordination space, and his current research interests are centered on synthesis and properties of porous coordination polymers/metal-organic frameworks.

Takafumi Ueno received his PhD from Osaka University, Japan in 1998. He held a position as an assistant professor at the Institute for Molecular Science in Okazaki, Japan. From 2002 to 2008, he worked as an assistant professor at Nagoya University and then took a position as an associate professor at the Institute for Integrated CellMaterial Sciences (iCeMS) at Kyoto University. In March 2012, he moved to the Tokyo Institute of Technology as a full professor. His current research

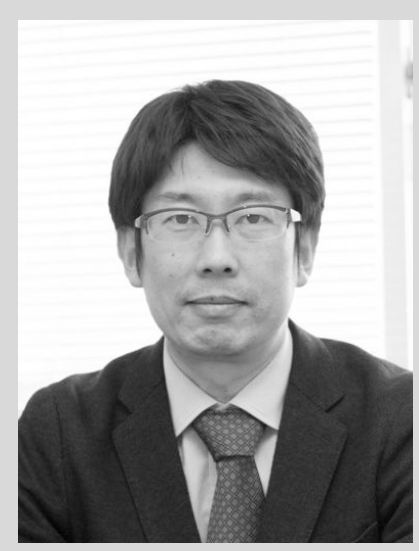

interests involve bioinorganic chemistry, molecular design of artificial metalloproteins and exploitation of meso-scale materials using protein assemblies. 
precise three-dimensional arrangements. Other natural and synthetic fibers are formed by self-assembly of peptides, proteins, and lipids. ${ }^{[5,12]}$ Amyloid-like fibers with diameters of less than $10 \mathrm{~nm}$ and lengths of up to a few micrometers consist of small peptides, partial fragments of natural proteins, or entire proteins (Figure $2 \mathrm{~d}$ ). ${ }^{[13]}$ Synthetic fibers or nanotubes are constructed by taking advantage of selfassembly of peptide amphiphiles and template synthesis (Figure 2e). ${ }^{[14-17]}$ To introduce functions into these nanostructures various strategies have been developed, including (1) chemical modifications of metal complexes, ${ }^{[18-}$ ${ }^{21]}$ (2) design of peptides with high affinity to metal ions, ${ }^{[22-}$ 26] (3) fusion of foreign enzymes, ${ }^{[27-30]}$ and (4) construction of artificial protein and peptide tubes. ${ }^{[31-36]}$

\subsection{Chemical modifications of metal complexes}

TMV is a plant virus consisting of 2130 identical capsid proteins (Figure 2a). It is one of the most widely used protein assemblies for integration of different metal compounds by chemical modifications of the interior and exterior of the virus. Francis and co-workers utilized TMV as a scaffold to construct light-harvesting systems by introducing covalently-bound donor and acceptor chromophores (Figure 3). ${ }^{[18-20]}$ Monomer proteins of TMV self-assemble into disc and rod structures. By chemical conjugation of donors and acceptors to cysteine residues of monomers, self-assembly of the different monomers forms the disc and rod structures that contain donors and acceptors at the designed positions that allow fluorescence resonance energy transfer (FRET) over a broad range of wavelengths. ${ }^{[18]}$ Arrangement of the ratio of labeled monomers and utilization of three types of chromophores has produced over $90 \%$ light transfer efficiency. Further study revealed that the rod can show higher energy transfer efficiency than the disc because the rod has a donor-todonor transfer system along the long axis, which cannot be formed by the disc structure. ${ }^{[19]}$ The regular and rigid structure of TMV provides the means to place the multiple synthetic molecules in a specific order with threedimensional arrangements according to specific designs.
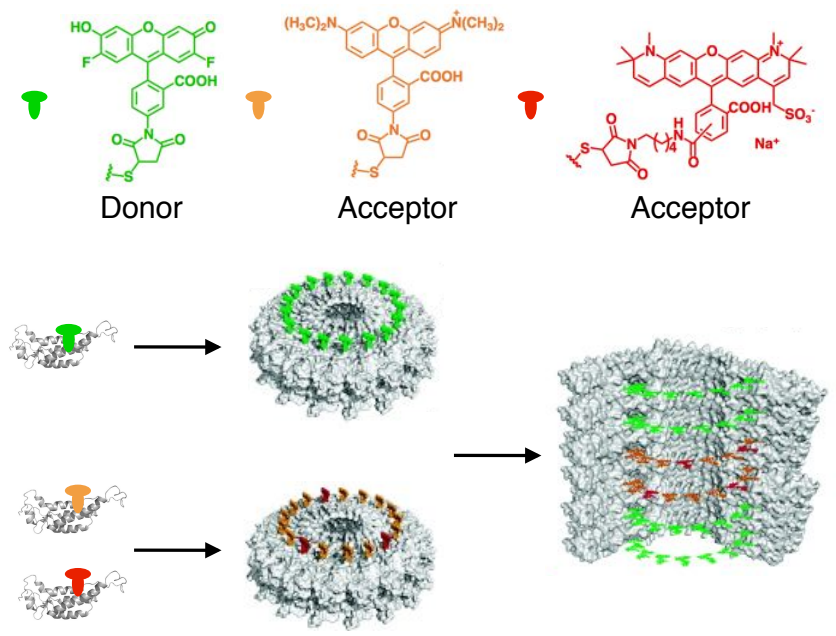

Figure 3. Self-assembling light harvesting systems based on chemical modification of donor and acceptor molecules to monomers of TMV and formation of disc and rod structures. Modified with permission from American Chemical Society, see ref. 18 .

\subsection{Design of peptides with high affinity to metal ions}

Korendovych, DeGrado and co-workers have demonstrated that amyloid fiber can be used to develop catalysts by providing coordination of $\mathrm{Zn}$ (II) ion on the fiber surface (Figure 4a). ${ }^{[37]}$ LKLKLKL peptide is known to selfassemble to form amyloid-like fibrils. Inspired by the natural enzyme archaeal $\gamma$-carbonic anhydride which has a catalytic site that includes His coordination to $\mathrm{Zn}$ (II) ion, an acetyl-LHLHLHL-amide peptide was produced and found to be capable of binding $\mathrm{Zn}(\mathrm{II})$. Another modified peptide, acetyl-IHIHIQI-amide was found to have the highest catalytic activity and forms amyloid fibrils in the presence of $\mathrm{Zn}$ (II) ion. Large numbers of catalytically active sites can be constructed on the surface of the fibers.

M13 virus contains 2700 major coat proteins (pVIII) and 5 minor coat proteins (pIX, pVII, pVI, and pIII) at their termini (Figure $2 b$ ). Each of the coat proteins of M13 virus can be separately modified with peptides and synthetic molecules. Belcher and co-workers have established a strategy that utilizes the M13 virus for photocatalytic reactions which includes anchoring of metal ions to metal-binding peptides on the surface. ${ }^{[23,38-40]}$ Au-Pt core-shell nanowires have been constructed by using the M13 virus as a template. ${ }^{[23]}$ Au-binding peptide (VSGSSPDS) was genetically introduced on the surface of M13 virus. An Au nanowire was formed by the addition of $\mathrm{Au}$ (III) ion to the M13 virus and further reduction. Addition of Pt(IV) ion into the $\mathrm{Au}$ nanowire followed by addition of ascorbic acid produces Pt shells on the surface of the Au nanowire. The Au-Pt core-shell nanowires have higher catalytic activities for oxidation of $\mathrm{CO}$ and ethanol compared to a commercial Pt catalyst. A notable example is co-assembly of photosensitizers and catalysts on the surface of the M13 virus using strategies which include both chemical modification and deposition of metal ions (Figure 4b). ${ }^{[39]}$ As a photosensitizer, $\mathrm{Zn}(\mathrm{II})$ deuteroporphyrin IX 2,4 bisethylene glycol (ZnDPEG) was coupled to two primary amines (N-terminus and lysine) of the M13 virus via a carbodiimide reaction. Subsequently, an iridium oxide hydrogen cluster was immobilized on the surface of the M13 virus by using the $\mathrm{IrO}_{2}$ binding peptide (AGETQQAM). The $\mathrm{IrO}_{2}-\mathrm{ZnDPEG}$ M13 virus nanowire was found to accelerate the process of light-driven water oxidation via a synergistic effect that includes (1) excitonic migration between ZnDPEGs and (2) a proximity effect between $\mathrm{ZnDPEG}$ and $\mathrm{IrO}_{2}$. By using M13 virus as a rigid template, different functional molecules can be aligned with tunable orientations and distances.

\subsection{Fusion of foreign enzymes}

PVX consists of 1270 capsid proteins (Figure 2c). PVX was utilized to produce an array of lipase enzymes on the surface by genetic fusion (Figure 5). ${ }^{[2]}$ Monomer proteins of PVX were genetically fused to lipase B derived from Candida antartica (CALB). Capsid protein (CP) of PVX and CALB was connected by a specific peptide known as $2 A$. Since protein production is occasionally interrupted at the $2 \mathrm{~A}$ site, a PVX assembly partially decorated with CALB was constructed by self-assembly of CALB-2A-CP and CP in vivo. The CALB-anchored PVX complex is catalytically 


\section{Running title}

active and remains functional even when it is deposited on a glass surface. This indicates that the CALB structure is stabilized on the PVX surface. This strategy will be extended to anchoring of metalloenzymes.

\section{a}

acetyl-LHLHLHL-amide

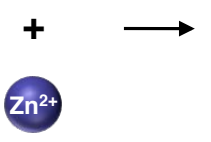

b
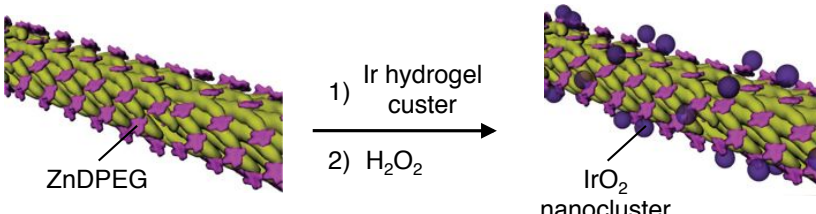

Figure 4. (a) Formation of $\mathrm{Zn}(\mathrm{II})$-binding amyloid fibrils by ligation of His. (b) Construction of photocatalytic nanostructures based on M13 virus by chemical modification of ZnDPEG and immobilization of $\mathrm{IrO}_{2}$ nanocluster. Reproduced for (a) and (b) with permission from Nature publishing group, see ref. 37 and 39 .

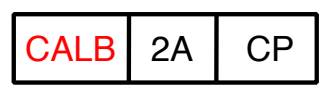

\section{$\mathrm{CP}$}

In vivo assembly

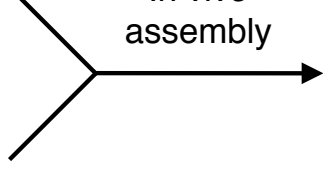

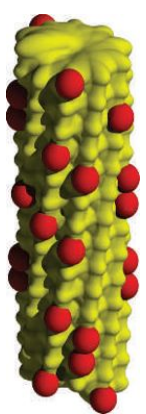

Figure 5. Immobilization of CALB on PVX by in vivo selfassembly of CALB-2A-CP and CP. Reproduced with permission from Nature publishing, see ref. 27.

\subsection{Artificial protein and peptide tubes}

Synthetic nanotubes formed by peptides, proteins, or lipids have been utilized in various applications such as development of nanoreactors, photocatalysts, and extracellular matrices. ${ }^{[31,32]}$ Shimizu and co-workers constructed a molecular recognition system based on FRET from donors immobilized on the inner channels of lipid nanotubes to an acceptor-labeled guest protein, ferritin. ${ }^{[32]}$ This system provides the ability to estimate the diffusion constants of the guest molecules with various size and surface charge in the nanochannels. Stupp and co-workers utilized peptide amphiphile (PA) nanofibers to control the release of carbon monoxide $(\mathrm{CO})$ in efforts to characterize its role as a therapeutic signal molecule. ${ }^{[33]}$ PA nanofibers were modified to include a ruthenium tricarbonyl moiety. The one-dimensional nanofibers release $\mathrm{CO}$ to improve cell viability against oxidative stress. Komatsu and co-workers synthesized protein-based nanotubes to achieve catalytic reactions. ${ }^{[34-36]}$ Nanotubes possessing $\alpha-\mathrm{Fe}_{2} \mathrm{O}_{3}$ nanoparticles were synthesized based on iron-storage protein, ferritin. ${ }^{[34]}$ Layer-by-layer accumulation of poly-L-arginine (PLA) and ferritin into a track-etched polycarbonate membrane was performed to generate protein nanotubes. Calcination of the PLA/ferritin nanotube results in removal of protein shells and PLA layers and produces $\alpha-\mathrm{Fe}_{2} \mathrm{O}_{3}$ nanoparticles on the outer walls. The $\alpha-\mathrm{Fe}_{2} \mathrm{O}_{3}$ nanotubes have photocatalytic activity and degrade 4-chlorophenol more efficiently than bulk $\alpha-\mathrm{Fe}_{2} \mathrm{O}_{3}$. Protein nanotubes with enzymes located on the interior surface were synthesized using a similar strategy. ${ }^{[35,36]}$ Layer-by-layer assembly of human serum albumin and PLA followed by addition of $\alpha$-glucosidase $(\alpha-$ GluD) into the polycarbonate membrane yielded protein nanotubes with $\alpha$-GluD inside the nanotubes (Figure 6). ${ }^{[35]}$ The nanotubes catalyze hydrolysis of 4-methyl-umbelliferyl$\alpha$-D-glucopyranoside (MUGlc) within the one-dimensional channels. These reports demonstrate the potential of tubular assemblies of proteins and peptides for preparation and integration of metal functions.

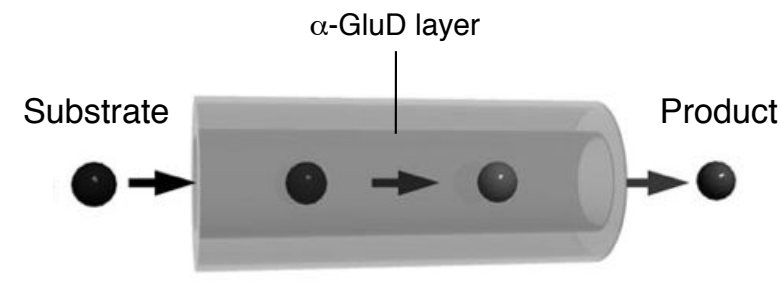<smiles>Cc1cc(=O)oc2cc(C(O)C(O)OC(C)CO)ccc12</smiles>

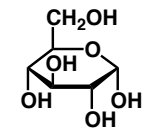

Figure 6. Catalytic hydrolytic reaction of MUGIc in channels constructed by protein nanotube with $\alpha-$ GluD interior surface. Modified with permission from Wiley, see ref. 35.

\section{Protein needle from bacteriophage T4}

Tailed bacteriophages utilize protein needles to penetrate cells during the infection process. Bacteriophage T4 consists of more than 40 component proteins which form distinct assembly structures such as the capsid head, whisker, tail fiber, and baseplate (Figure 7a). ${ }^{[41,42]}$ It is hypothesized that these component proteins act cooperatively to enable efficient puncture of host cells and subsequent injection of DNA. ${ }^{[41,43,44]}$ The baseplate is a molecular machine that 


\section{Running title}

controls the infection pathway and plays roles in cell recognition, penetration, and DNA injection (Figure 7b). ${ }^{[45]}$ (gp27-gp5) ${ }_{3}$ (gp: gene product) is a protein needle structure located at the center of the baseplate which serves to penetrate the outer membrane of E. coli. ${ }^{[41,42,45]}$ The gp27 trimer forms a 5-nm long hollow cylinder, and gp5 trimer forms a 14-nm long needle to form a "torch handle" structure (Figure 7c). ${ }^{[45]}$ The estimated infection process driven by (gp27-gp5) $)_{3}$ is shown in Figure $8 .^{[41]}$ Infection is initiated by binding of the tail fibers of bacteriophage T4 to lipopolysaccharide on the surface of $E$. coli (Figure 8a). The binding signal is transmitted to anchor the baseplate to the cell membrane and then the structure of the baseplate is altered to induce contraction of the tail sheath (Figure $8 \mathrm{~b}$ ). The contraction generates force at the top of (gp27-gp5) which is then directed to cell membrane, causing penetration into the outer section of the cell membrane (Figure 8c). After penetration of $(\mathrm{gp} 5)_{3}$, the lysozyme domain of $(\mathrm{gp} 5)_{3}$ is activated and digests the peptidoglycan layer (Figure $8 \mathrm{~d}$ and 8e). Finally, DNA injection is initiated. It is currently thought that the DNA injection is initiated by interaction of $(\mathrm{gp} 27)_{3}$ with a receptor on the cytoplasmic membrane (Figure $8 \mathrm{f}$ ). The $\mathrm{C}$-terminal of $(\mathrm{gp} 5)_{3}$ consists of a robust needle domain formed of a triple-stranded $\beta$-helix. Thus, the $\beta$-helix domain is expected to play a critical role in the cell penetrating pathway which includes infection and protein translocation.

\section{a}

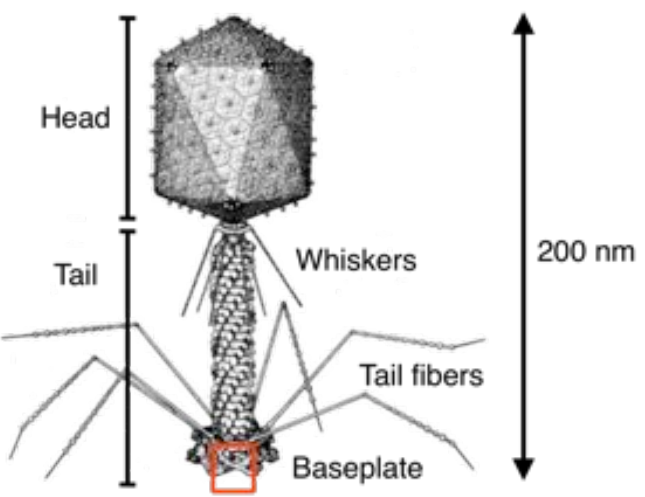

b

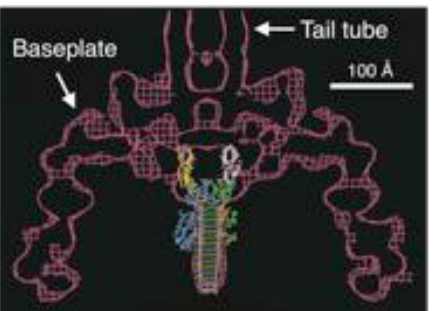

$c$

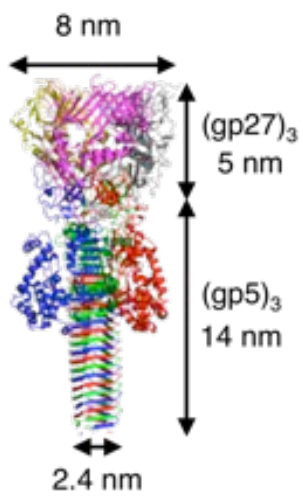

Figure 7. (a) Bacteriophage T4. (b) Cross-sectioned density fitted with the atomic structure of $(\mathrm{gp} 27-\mathrm{gp} 5)_{3}$. (c) Crystal structure of (gp27-gp5) $)_{3}$ (PDB ID: 1K28). Modified with permission for (a) and (b) from Springer and Nature publishing group, respectively, see ref. 41 and 45 .

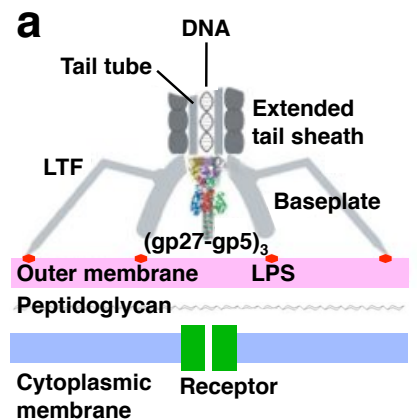

b

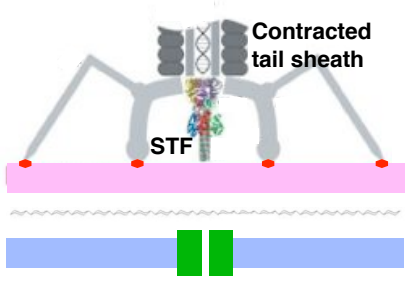

C

d
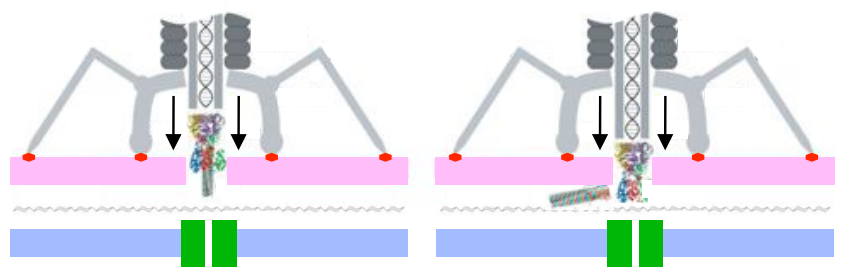

e

$\mathbf{f}$
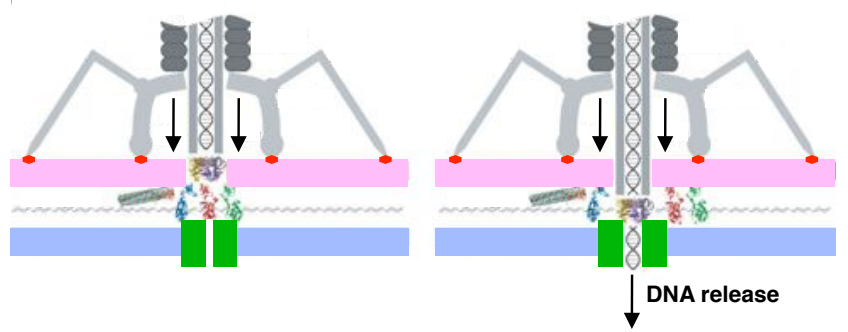

Figure 8. Infection process of bacteriophage T4. (a) Recognition of $E$. coli by tail fibers. (b) Attachment of the baseplate to cell surface and contraction of tail sheath. (c) Penetration of (gp27-gp5) $)_{3}$ into outer cell membrane. (d) Dissociation of C-terminal of (gp5) $)_{3}$. (e) Release of lysozyme domains to digest peptidoglycan layer. (f) DNA release into cytoplasm. Modified with permission from Springer, see ref. 41 .

\subsection{Unique assembly of the needle by using protein inorganic hybrid synthesis}

The unique structural features of (gp27-gp5) $)_{3}$ motivated us to investigate it as a molecular template for creating artificial metalloenzymes by modifying it with inorganic metal complexes. ${ }^{[3,46]}$ The needle structure of $(\mathrm{gp} 5)_{3}$ has been utilized as a component for in situ synthesis of a tetrapod assembly (Figure 9). ${ }^{[47]}$ A triad of (His) ${ }_{6}$ fragments, which exhibit a high affinity for metal cations and nanoclusters, were introduced at the C-termini of the gp5 monomer to generate three-dimensional structures upon nanoclusterization of gold ions at the (His) ${ }_{6}$ fragments. This assembly was found to generate gold nanoclusters upon reduction with $\mathrm{NaBH}_{4}$ (Figure 9a). The Au-needle composite structure is comprised of tetrapod assemblies with four (gp5) $)_{3}$ of approximate lengths of $14 \mathrm{~nm}$ as observed in TEM (Figure 9b). This matches with the size of

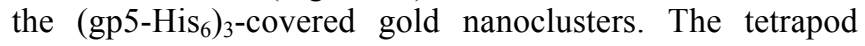
structure was selectively constructed due to the electrostatic repulsion of a negatively-charged region located at the $\mathrm{C}$ terminus of $(\mathrm{gp} 5)_{3}$. The strategy to design well-defined 
protein assembly will be applied to construct unique assembly structures of artificial metalloenzymes.

\section{a}

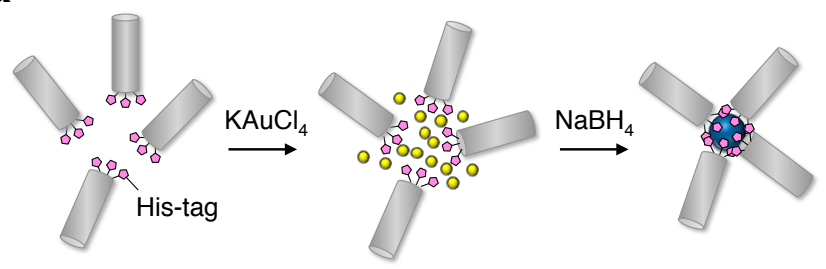

b
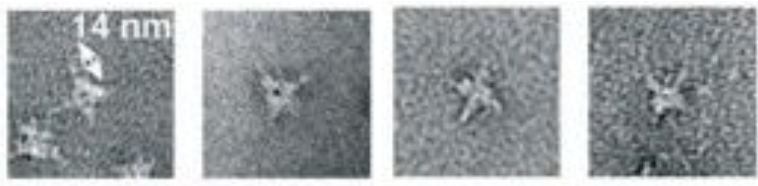

Figure 9. (a) Construction of tetrapod assembly of $(\mathrm{gp} 5)_{3}$ via formation of Au nanocluster. (b) TEM images of the tetrapod assembly.

\subsection{Utilization of a nanocup of the needle as a chemical reactor}

The cup-shaped structure of (gp27-gp5) ${ }_{3}$ has been utilized as a nanoenvironment for catalytic reactions (Figure 10). ${ }^{[4]} \mathrm{A}$ cysteine residue was introduced at the top of $(\mathrm{gp} 5)_{3}$ which is located at the bottom of the bio-nanocup. Using a conjugation reaction between the cysteine residue and the maleimide moiety, $\mathrm{Fe}(\mathrm{III})$ protoporphyrin units were successfully modified on the inside of the cup constructed from (gp27-gp5) $)_{3}$ (Figure 10a). Crystal structure analysis and MALDI-TOF confirmed complete modification of the $\mathrm{Fe}$ (III) protoporphyrin units (Figure 10b). $\mathrm{H}_{2} \mathrm{O}_{2}$-dependent sulfoxidation of thioanisole catalyzed by the composites was evaluated. The catalytic efficiency was found to be 6-10 times greater than that of $\mathrm{Fe}(\mathrm{III})$ protoporphyrin complex. The acceleration of the catalytic reactions is expected to be due to the hydrophobic environment formed by the attachment of $(\mathrm{gp} 27)_{3}$ to the top of $(\mathrm{gp} 5)_{3}$.

\section{a}

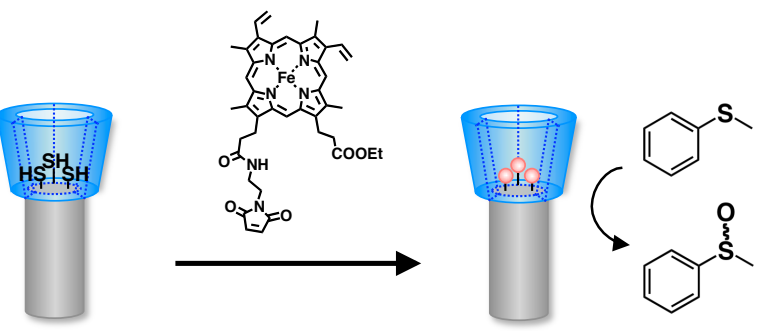

b
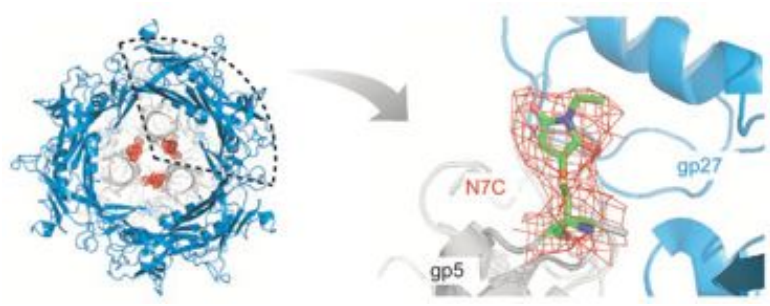

Figure 10. (a) A schematic drawing of construction of $\mathrm{Fe}(\mathrm{III})$ protoporphyrin-(gp27-gp5) ${ }_{3}$ composite and sulfoxidation reaction. (b) A top view and close-up view of the crystal structure of $\mathrm{Fe}(\mathrm{III})$ protoporphyrin-gp5-gp27 composite.

\subsection{An energy transfer system in the nanocup of the needle produced by hetero-modifications}

The cup structure of (gp27-gp5) 3 was utilized to construct an energy transfer system (Figure 11). ${ }^{[49]}$ FRET was observed by hetero-modification of two types of fluorescence molecules that can induce FRET (using fluorescein (Fl) as a donor and tetramethylrhodamine (TMR) as acceptor) to cysteine residues of $(\mathrm{gp} 5)_{3}$ and $(\mathrm{gp} 27)_{3}$. After the first modification of F1- or TMR-maleimide to the cysteine residue at the top of the (gp5) $)_{3}$ unit, three gp27 monomers were assembled on the modified (gp5) 3 composites. Then the second modification of TMR- or Fl-maleimide to the cysteine residue at the top of the $(\mathrm{gp} 27)_{3}$ unit was achieved. The modification steps were tracked by reverse-phase HPLC and MALDI-TOF. The most efficient FRET was observed when F1 and TMR were modified into $(\mathrm{gp} 5)_{3}$ and $(\mathrm{gp} 27)_{3}$, respectively. On the other hand, alternating the TMR and F1 conjugation sites induces significant fluorescence selfquenching of TMR. These results suggest that the needle and cup structures of $(\mathrm{gp} 27-\mathrm{gp} 5)_{3}$ provide useful templates for precise placement of functional molecules on their surfaces.
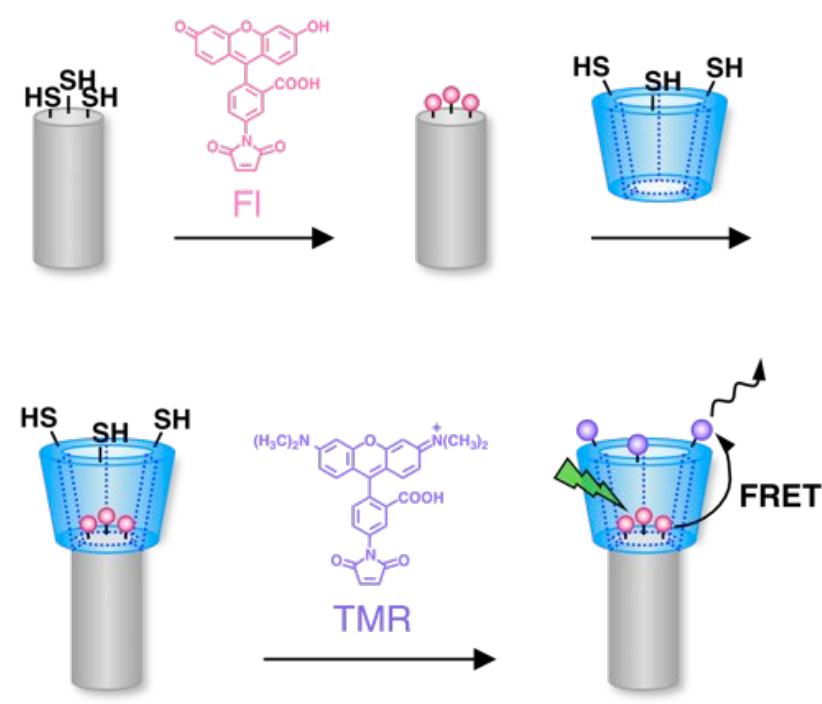

Figure 11. Schematic representation of hetero-modification of $\mathrm{FI}$ (donor) and TMR (acceptor) on (gp27-gp5) ${ }_{3}$ to induce FRET.

\section{Artificial protein needle composed of triple- stranded $\beta$-helix}

(gp27-gp5) 3 has been used as a unique molecular template for creation of artificial metalloenzymes. However, the stability of (gp27-gp5) 3 is not sufficient for it to tolerate the harsh conditions required for chemical modification and catalytic reactions. Therefore we have constructed a more robust needle by integration of the $\beta$-helix motif of $(\mathrm{gp} 5)_{3}$ and foldon, a trimer of bacteriophage T4 fibritin (Figure 12). ${ }^{[50]}$ The most stable region of the $\beta$-helix in the $C$ terminal of (gp5) $)_{3}$ was investigated by proteolytic digestion 


\section{Running title}

and identified as the 490-575 fragment of gp5. Since the $\beta$ helix tends to form multimeric aggregates resulting from head-to-head or head-to-tail interactions, foldon was genetically fused to the C-terminus of the 490-575 fragment of gp5 to inhibit random aggregation. ${ }^{[50]}$ The chimeric protein, gp5 $\beta$-helix foldon (gp5 $\beta \mathrm{f}$ ) forms a trimer-dimer structure $\left[(\mathrm{gp} 5 \beta \mathrm{f})_{3}\right]_{2}$ in solution with head-to-head dimerization at the $\mathrm{N}$-terminus of $(\mathrm{gp} 5 \beta \mathrm{f})_{3}$. The crystal structure of $\left[(\mathrm{gp} 5 \beta \mathrm{f})_{3}\right]_{2}$ shows that the needle structure as a length of $16 \mathrm{~nm}$ and a diameter of $2.4 \mathrm{~nm}$ (Figure 12). $\left[(\mathrm{gp} 5 \beta \mathrm{f})_{3}\right]_{2}$ has high stability under various conditions such as high temperatures $\left(<100^{\circ} \mathrm{C}\right), \mathrm{pH}(2-10)$, and the presence of organic solvents $(50-70 \%)$. Thus, because of the regular alignment of amino acid residues on the $\beta$-helix surface and its high stability, $\left[(\mathrm{gp} 5 \beta \mathrm{f})_{3}\right]_{2}$ is an ideal molecular template for alignment of metal complexes on the outer surface.

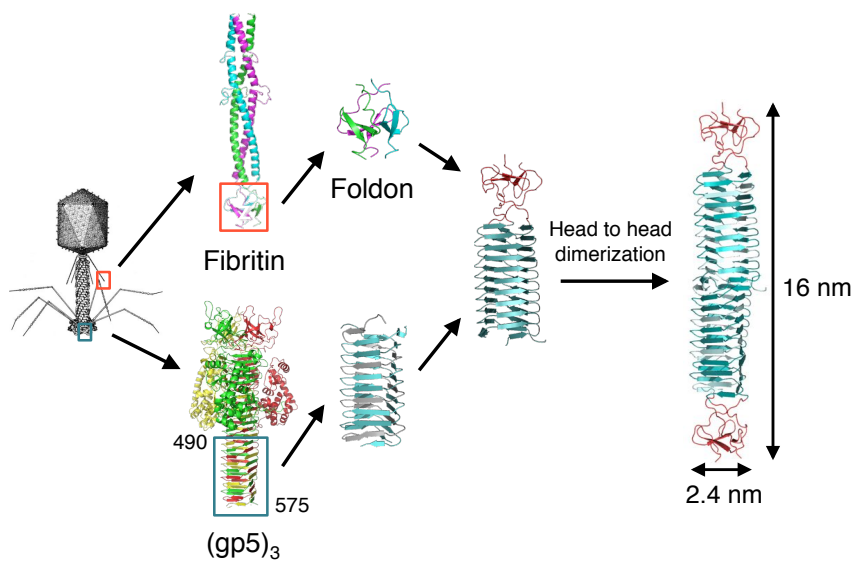

Figure 12. Construction of $\left[(\mathrm{gp} 5 \beta \mathrm{f})_{3}\right]_{2}$ from triple-stranded $\beta$ helix of gp5 and foldon of fibritin of bacteriophage T4.

\subsection{Alignment of ligand molecules on the needle to construct reaction fields}

Flavin molecules were chemically conjugated to Lys residues aligned on the triangular plane of $\left[(\mathrm{gp} 5 \beta \mathrm{f})_{3}\right]_{2}$ along with the $\beta$-helix at $10-15 \AA$ intervals (Figure 13). ${ }^{[50]}$ The flavin molecules were found to be completely modified and the structural and conformational integrity of the $\beta$-helix structure is retained (Figure 13a). The flavin-needle composite accelerates the rate of an azide-alkyne $[3+2]$ cycloaddition in the presence of $\mathrm{Cu}(\mathrm{I})$ ion with 33 times higher efficiency than that of a polyLys-flavin composite (Figure 13b). It is essential to form a $\mathrm{Cu}(\mathrm{I})$ monocoordination structure to accelerate the catalytic reaction. Thus, the flavin moieties aligned on $\left[(\mathrm{gp} 5 \beta \mathrm{f})_{3}\right]_{2}$ exhibit high reactivity as a result of the structural restriction which maintains the mono-coordination geometry on the surface. In contrast, the polyLys-flavin composite forms aggregates under the same reaction conditions. Thus, the structural integrity of $\left[(\mathrm{gp} 5 \beta \mathrm{f})_{3}\right]_{2}$, even after modification to include hydrophobic flavin molecules on its surface, has enhanced affinity for metal ions which serve as catalysts.

\subsection{A photocatalytic reaction driven by electron transfer between $\mathrm{Ru}$ and Re complexes on the needle}

Alignment of different types of metal complexes, Ru(bpy $)_{3}$ and $\mathrm{Re}(\mathrm{bpy})(\mathrm{CO})_{3} \mathrm{Cl}$ on the surface of $\left[(\mathrm{gp} 5 \beta \mathrm{f})_{3}\right]_{2}$ improves
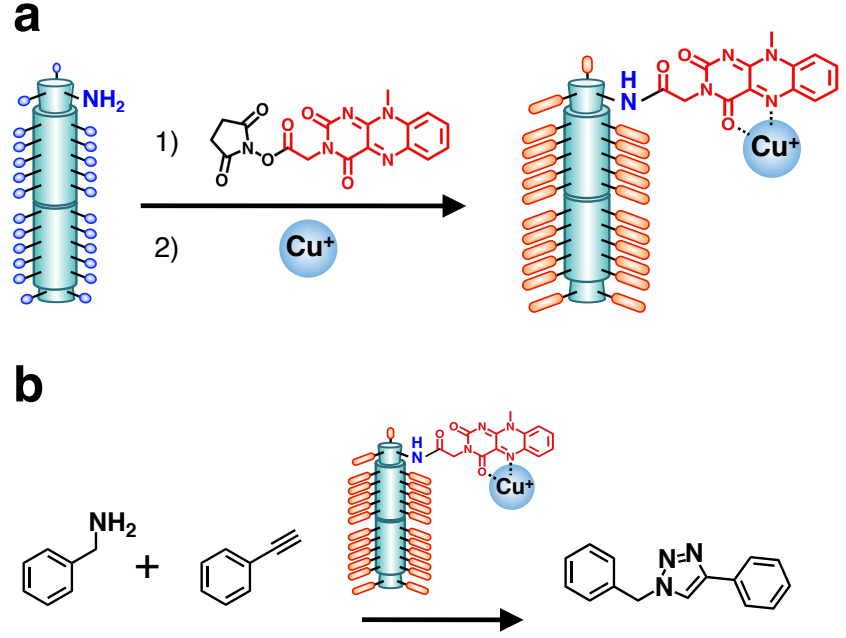

Figure 13. (a) Modification of flavin molecules to primary amines of $\left[(\mathrm{gp} 5 \mathrm{\beta f})_{3}\right]_{2}$ and complexation with $\mathrm{Cu}(\mathrm{I})$ ion. (b) Azide-alkyne $[3+2]$ cycloaddition reaction catalyzed by the composite.

the photocatalytic system by enhancing the rate of electron transfer between the metal complexes (Figure 14). ${ }^{[51]}$ Stepwise chemical modifications of Cys and Lys were carried out in the dual modification (Figure 14a). The electron transfer reaction from the photo-reduced $\mathrm{Ru}$ moiety to the Re moiety for reduction of $\mathrm{CO}_{2}$ to $\mathrm{CO}$ is accelerated when $\mathrm{Ru}(\mathrm{bpy})_{3}$ and $\mathrm{Re}(\mathrm{bpy})(\mathrm{CO})_{3} \mathrm{Cl}$ complexes are adjacent to each other (Figure 14b). Thus, Cys residues were introduced by site-directed mutagenesis to the positions that are adjacent to Lys residues on the surface of $\left[(\mathrm{gp} 5 \beta \mathrm{f})_{3}\right]_{2}$ to induce an electron transfer reaction between the $\mathrm{Ru}$ and $\mathrm{Re}$ mononuclear complexes. The cysteine residues were modified with $\operatorname{Re}($ bpy $)(\mathrm{CO})_{3} \mathrm{Cl}$ by conjugation to the maleimide moiety. Subsequently, Lys residues were modified with $\mathrm{Ru}(\mathrm{bpy})_{3}$ by conjugation of the succinic anhydride moiety. Under irradiation with visible light $(\geq 500$ $\mathrm{nm})$, the photo-catalytic reduction of $\mathrm{CO}_{2}$ is accelerated by the cooperative reaction of the $\mathrm{Ru}$ and $\mathrm{Re}$ complexes on the surface of $\left[(\mathrm{gp} 5 \beta \mathrm{f})_{3}\right]_{2}$ in the presence of 1-benzyl-1,4dihydronicotinamide (BNAH). The turnover frequency per hour for $\mathrm{CO}$ production per Re ion of $\left[(\mathrm{gp} 5 \beta \mathrm{f})_{3}\right]_{2}$ modified with $\mathrm{Re}$ and $\mathrm{Ru}$ complexes was 3.3 times higher than that of a mixture of $\mathrm{Ru}(\mathrm{bpy})_{2}$-[4-(2-carboxylethyl)-4'-methyl-2,2'bipyridyl $]\left(\mathrm{PF}_{6}\right)_{2}(\mathrm{Ru}-\mathrm{COOH})$ and $\left[(\mathrm{gp} 5 \beta \mathrm{f})_{3}\right]_{2}$ modified with the Re complex. The improvement of the reactivity is due to the proximity effect of the $\mathrm{Ru}$ and $\mathrm{Re}$ moieties on the $\left[(\mathrm{gp} 5 \beta \mathrm{f})_{3}\right]_{2}$. The results indicate that the positions of the different types of metal complexes can be optimized to accelerate catalytic reactions by adding and removing key residues, such as Lys, Cys and Tyr which are used in bioconjugation reactions.

\subsection{Semi-synthesis of catalytic active Sc complex on the needle}

The strategy of inserting metal complexes at specific locations on the surface of $\left[(\mathrm{gp} 5 \beta \mathrm{f})_{3}\right]_{2}$ was extended to semi-synthesis of catalytically active metal complexes in situ (Figure 15). ${ }^{[52]}$ An artificial Sc(III) enzyme was 
a

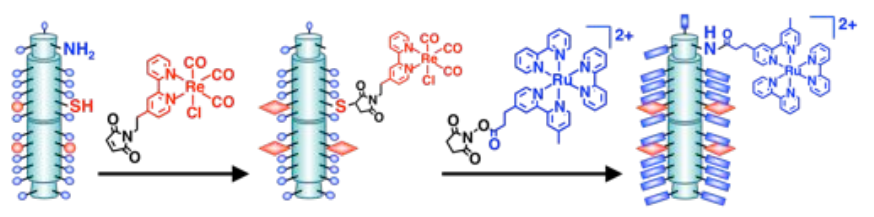

b

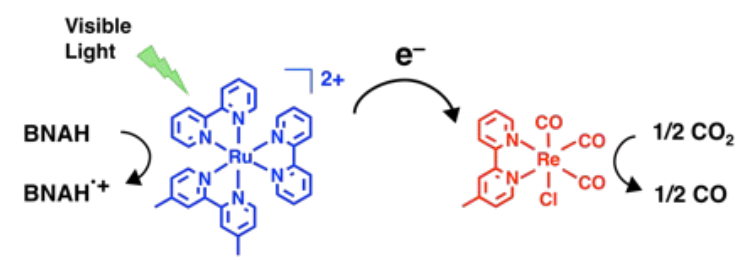

Figure 14. (a) Hetero-modification of Re and Ru complexes to Cys and Lys residues on $\left[(\mathrm{gp} 5 \beta \mathrm{f})_{3}\right]_{2}$, respectively. (b) Photocatalytic reduction of $\mathrm{CO}_{2}$ to $\mathrm{CO}$ by electron transfer from $\mathrm{Ru}$ to Re complex by addition of BNAH under irradiation of visible light.

constructed by combining a conjugated 2,2'-bipyridine (bpy) ligand and - $\mathrm{ROH}$ groups of Thr and Ser on the surface of $\left[(\mathrm{gp} 5 \beta \mathrm{f})_{3}\right]_{2}$. Tetradentate coordination of the bpy and two $-\mathrm{ROH}$ groups to the $\mathrm{Sc}(\mathrm{III})$ ion is essential to produce the $\mathrm{Sc}$ complex, which is capable of catalyzing various epoxide ring-opening reactions. The two $-\mathrm{ROH}$ groups are replaced by alcohol groups of Thr or Ser residues of $\left[(\operatorname{gp} 5 \beta \mathrm{ff})_{3}\right]_{2}$. The bpy group was conjugated to cysteine residues that were designed and introduced at positions adjacent to the $-\mathrm{ROH}$ groups on $\left[(\mathrm{gp} 5 \beta \mathrm{f})_{3}\right]_{2}$ (Figure 15a). Addition of $\mathrm{Sc}(\mathrm{III})$ ions to the bpy-modified $\left[(\operatorname{gp} 5 \beta \mathrm{f})_{3}\right]_{2}$, provided the semisynthesized Sc(III) complex with the ability to catalyze an epoxide ring-opening reaction with a $42 \%$ conversion rate (Figure 15b). The conversion was more than 20 times higher than that produced by mixtures of $\left[(\mathrm{gp} 5 \mathrm{\beta f})_{3}\right]_{2} / 2,2$-bipyridine and L-threonine/2,2-bipyridine. These results indicate that the catalytically active $\mathrm{Sc}(\mathrm{III})$ complex is obtained only when 2,2-bipyridine is in a position adjacent to two alcohol groups of Thr aligned on surface of $\left[(\mathrm{gp} 5 \mathrm{\beta f})_{3}\right]_{2}$. This work shows that the semi-synthetic approach is a useful strategy for construction of new artificial metalloenzymes in situ by combining a simple synthetic ligand and natural coordinating amino acids on the host proteins. These results demonstrate that $\left[(\mathrm{gp} 5 \beta \mathrm{f})_{3}\right]_{2}$ is a useful platform for constructing stable and robust artificial metalloenzymes by attachment of metal complexes to amino acid residues on the protein surface.

\section{Summary and Outlook}

Protein assemblies have a broad range of unique structures and functions, uniform individual sizes, and diverse functional groups. As a result, they have the potential to serve as molecular platforms for construction of artificial metalloenzymes. The anisotropic structures of tube proteins and fiber proteins which have high surface areas can be manipulated by molecular biology and synthetic chemistry techniques to produce linked and regularly aligned synthetic molecules, metal complexes, metal nanoparticles, and a

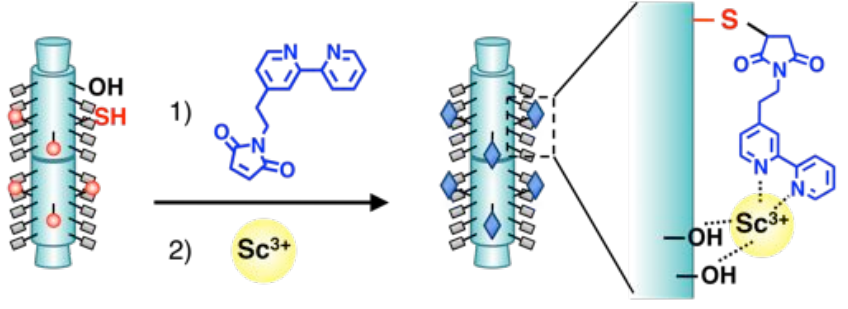

b

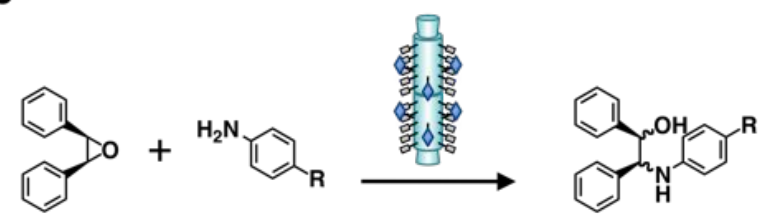

Figure 15. Semi-synthesis of Sc(III) catalyst on the surface of $\left[\left(\mathrm{gp} 5 \mathrm{\beta f}_{3}\right)_{2}\right]_{2}$. (a) Modification of bpy ligand to Cys residues of $\left[(\mathrm{gp} 5 \beta \mathrm{ff})_{3}\right]_{2}$, and complexation with the $\mathrm{Sc}(\mathrm{III})$ ion. (b) Epoxide ring-opening reaction by the composite.

enzymes for use in various applications such as electronic devices, cascade reactions, and photocatalytic reactions. In addition, integration of different types of functions on a surface by hetero modifications can produce assemblies with high catalytic efficiency.

Although protein tubes and fibers are frequently used as molecular templates, some of them are flexible and low stable. We have constructed a robust protein needle from a triple-stranded $\beta$-helix and the foldon fragment of bacteriophage T4. This engineered needle has high thermal and chemical stability which allows it to tolerate the harsh conditions required for chemical conjugations and catalytic reactions. ${ }^{[50]}$ Analysis of the crystal structure of the needle inspired us to arrange several metal complexes at specific locations on the surface of the needle. These assemblies are more efficient catalysts then the corresponding bulk metal complex systems. ${ }^{[50-52]}$ The high stability and regularity of the needle provides it with the potential to use component proteins of natural supramolecules as building blocks.

Since structures of protein assemblies are optimized to serve their functions in cells, intracellular applications of the protein assemblies are promising. Viruses are widely utilized in biological applications such as phage display, drug delivery systems, and cellular imaging. ${ }^{[53,54]}$ Because bacteriophage T4 uses a protein needle for cell penetration (Figure 7 and 8), we expect that the cell-penetrating characteristics of the needle can be harnessed for construction of new types of artificial metalloenzymes. Intracellular catalytic reactions will be proceeded by metal complex catalysts conjugated with the needle. This approach is expected to open up a new field of use of artificial metalloenzymes based on the combination of natural cell-penetrating characteristics of protein needles and synthetic metal complexes by taking advantage of advances in biotechnology, molecular biology and supramolecular technology. 


\section{Acknowledgements}

Parts of this work were supported by the Funding Program for Next Generation World-Leading Researchers (for T.U.), and Research Fellowship for Young Scientists (for H.I.) from the Japan Society for the Promotion of Science. iCeMS is supported by the World Premier International Research Initiative (WPI), MEXT, Japan.

\section{References}

[1] M. Uchida, M. T. Klem, M. Allen, P. Suci, M Flenniken, E. Gillitzer, Z. Varpness, L. O. Liepold, M. Young, T. Douglas, Adv. Mater. 2007, 19, 1025-1042.

[2] D. Papapostolou, S. Howorka, Mol. Biosyst. 2009, 5, 723-732.

[3] N. J. M. Sanghamitra, T. Ueno, Chem. Commun. 2013, 49, 4114-4126.

[4] T. Ueno, H. Tabe, Y. Tanaka, Chem. Asian J. 2013, 8, $1646-1660$

[5] D. N. Woolfson, Z. N. Mahmoud, Chem. Soc. Rev. 2010, 39, 3464-3479.

[6] D. Cardinale, N. Carette, T. Michon, Trends Biotechnol. 2012, 30, 369-376.

[7] Y. Maeda, H. Matsui, Soft Matter 2012, 8, 7533-7544.

[8] C. Sachse, J. Z. Chen, P.-D. Coureux, M. E. Stroupe, M. Fändrich, N. Grigorieff, J. Mol. Biol. 2007, 371, 812835.

[9] L. Parker, A. Kendall, G. Stubbs, Virology 2002, 300, 291-295.

[10] S.-Y. Lee, J.-S. Lim, M. T. Harris, Biotechnol. Bioeng. 2012, 109, 16-30.

[11] J.-H. Lee, J. H. Lee, Y. J. Lee, K. T. Nam, Curr. Opin. Biotechnol. 2013, 24, 599-605.

[12] X. Zhao, F. Pan, H. Xu, M. Yaseen, H. Shan, C. A. E. Hauser, S. Zhang, J. R. Lu, Chem. Soc. Rev. 2010, 39, 3480-3498.

[13] I. Cherny, E. Gazit, Angew. Chem. Int. Ed. 2008, 47, 4062-4069.

[14] T. Shimizu, M. Masuda, H. Minamikawa, Chem. Rev. 2005, 105, 1401-1444.

[15] T. Komatsu, Nanoscale 2012, 4, 1910-1918.

[16] M. J. Webber, E. J. Berns, S. I. Stupp, Isr. J. Chem. 2013, 53, 530-554.

[17] J. D. Hartgerink, E. Beniash, S. I. Stupp, Science 2001, 294, 1684-1688.

[18] R. A. Miller, A. D. Presley, M. B. Francis, J. Am. Chem. Soc. 2007, 129, 3104-3109.

[19] R. A. Miller, N. Stephanopoulos, J. M. McFarland, A. S. Rosko, P. L. Geissler, M. B. Francis, J. Am. Chem. Soc. 2010, 132, 6068-6074.

[20] M. T. Dedeo, K. E. Duderstadt, J. M. Berger, M. B. Francis, Nano Lett. 2010, 10, 181-186.

[21] Y. S. Nam, T. Shin, H. Park, A. P. Magyar, K. Choi, G. Fantner, K. A. Nelson, A. M. Belcher, J. Am. Chem. Soc. 2010, 132, 1462-1463.

[22] M. Kobayashi, M. Seki, H. Tabata, Y. Watanabe, I. Yamashita, Nano Lett. 2010, 10, 773-776.

[23] Y. Lee, J. Kim, D. S. Yun, Y. S. Nam, Y. Shao-Horn, A. M. Belcher, Energy Environ. Sci. 2012, 5, 8328-8334.

[24] C. Yang, A. K. Manocchi, B. Lee, H. Yi, Appl. Catal., B 2010, 93, 282-291.

[25] C. Yang, H. Yi, Biochem. Eng. J. 2010, 52, 160-167.

[26] B. Neltner, B. Peddie, A. Xu, W. Doenlen, K. Durand, D. S. Yun, S. Speakman, A. Peterson, A. Belcher, $A C S$ Nano 2010, 4, 3227-3235.

[27] N. Carette, H. Engelkamp, E. Akpa, S. J. Pierre, N. R. Cameron, P. C. M. Christianen, J. C. Maan, J. C. Thies,
R. Weberskirch, A. E. Rowan, et al., Nat. Nanotechnol. 2007, 2, 226-229.

[28] S. M. Pilkington, S. J. Roberts, S. J. Meade, J. A. Gerrard, Biotechnol. Prog. 2010, 26, 93-100.

[29] U. Baxa, V. Speransky, A. C. Steven, R. B. Wickner, Proc. Natl. Acad. Sci. U.S.A. 2002, 99, 5253-5260.

[30] A. J. Baldwin, R. Bader, J. Christodoulou, C. E. MacPhee, C. M. Dobson, P. D. Barker, J. Am. Chem. Soc. 2006, 128, 2162-2163.

[31] E. Busseron, Y. Ruff, E. Moulin, N. Giuseppone, Nanoscale 2013, 5, 7098-7140.

[32] N. Kameta, M. Masuda, H. Minamikawa, Y. Mishima, I. Yamashita, T. Shimizu, Chem. Mater. 2007, 19, 35533560 .

[33] J. B. Matson, M. J. Webber, V. K. Tamboli, B. Weber, S. I. Stupp, Soft Matter 2012, 8, 6689-6692.

[34] X. Qu, N. Kobayashi, T. Komatsu, ACS Nano 2010, 4, $1732-1738$.

[35] T. Komatsu, H. Terada, N. Kobayashi, Chem. Eur. J. 2011, 17, 1849-1854.

[36] T. Komatsu, T. Sato, C. Boettcher, Chem. Asian J. 2012, 7, 201-206

[37] C. M. Rufo, Y. S. Moroz, O. V. Moroz, J. Stöhr, T. A. Smith, X. Hu, W. F. DeGrado, I. V. Korendovych, Nat. Chem. 2014, 6, 303-309.

[38] K. T. Nam, D.-W. Kim, P. J. Yoo, C.-Y. Chiang, N. Meethong, P. T. Hammond, Y.-M. Chiang, A. M. Belcher, Science 2006, 312, 885-888.

[39] Y. S. Nam, A. P. Magyar, D. Lee, J.-W. Kim, D. S. Yun, H. Park, T. S. Pollom, D. A. Weitz, A. M. Belcher, Nat. Nanotechnol. 2010, 5, 340-344.

[40] C. Mao, Science 2004, 303, 213-217.

[41] P. G. Leiman, S. Kanamaru, V. V. Mesyanzhinov, F. Arisaka, M. G. Rossmann, Cell. Mol. Life Sci. 2003, 60, 2356-2370.

[42] M. G. Rossmann, V. V. Mesyanzhinov, F. Arisaka, P. G. Leiman, Curr. Opin. Struct. Biol. 2004, 14, 171-180.

[43] J. D. Karam, J. W. Drake, K. N. Kreuzer, G. Mosig, D. H. Hall in Molecular Biology of Bacteriophage T4 (Ed.: J. D. Karam), American Society for Microbiology, Washington DC, 1994.

[44] P. G. Leiman, F. Arisaka, M. J. van Raaij, V. A. Kostyuchenko, A. A. Aksyuk, S. Kanamaru, M. G. Rossmann, Virol. J. 2010, 7, 355.

[45] S. Kanamaru, P. G. Leiman, V. A. Kostyuchenko, P. R. Chipman, V. V. Mesyanzhinov, F. Arisaka, M. G. Rossmann, Nature 2002, 415, 553-557.

[46] T. Ueno, J. Mater. Chem. 2008, 18, 3741-3745.

[47] T. Ueno, T. Koshiyama, T. Tsuruga, T. Goto, S. Kanamaru, F. Arisaka, Y. Watanabe, Angew. Chem. Int. Ed. 2006, 45, 4508-4512.

[48] T. Koshiyama, N. Yokoi, T. Ueno, S. Kanamaru, S. Nagano, Y. Shiro, F. Arisaka, Y. Watanabe, Small 2008 , 4, 50-54.

[49] T. Koshiyama, T. Ueno, S. Kanamaru, F. Arisaka, Y. Watanabe, Org. Biomol. Chem. 2009, 7, 2649.

[50] N. Yokoi, H. Inaba, M. Terauchi, A. Z. Stieg, N. J. M. Sanghamitra, T. Koshiyama, K. Yutani, S. Kanamaru, F. Arisaka, T. Hikage, et al., Small 2010, 6, 1873-1879.

[51] N. Yokoi, Y. Miura, C.-Y. Huang, N. Takatani, H. Inaba, T. Koshiyama, S. Kanamaru, F. Arisaka, Y. Watanabe, S. Kitagawa, et al., Chem. Commun. 2011, 47, 2074-2076.

[52] H. Inaba, S. Kanamaru, F. Arisaka, S. Kitagawa, T. Ueno, Dalton Trans. 2012, 41, 11424-11427.

[53] F. Li, Q. Wang, Small 2013, 10, 230-245.
[54] Y. Ma, R. J. M. Nolte, J. J. L. M. Cornelissen, $A d v$. Drug Deliv. Rev. 2012, 64, 811-825. 
Running title

Received: ((will be filled in by the editorial staff))

Accepted: ((will be filled in by the editorial staff))

Published online: ((will be filled in by the editorial staff)) 